\title{
PODCAST PARA SURDOS?! A “ESCRITA ORAL” DE UMA TECNOLOGIA EDUCATIVA
}

\section{PODCAST FOR THE DEAFS?! THE "ORAL WRITING" OF AN EDUCATIONAL TECHNOLOGY}

\author{
FREIRE, Eugênio Paccelle Aguiar \\ paccellifreire@gmail.com \\ Universidade Federal do Rio Grande do Norte
}

RESUMO O podcast para surdos, por consistir na transcrição das falas dos programas, acaba por superar as definições educacionais vigentes que, ao analisar o podcast, entende-o como uma ferramenta caracterizada pelo uso do áudio digital. Assim, desenvolve-se na área uma significativa lacuna: como definir a natureza de um podcast que suplanta seu meio tecnológico? Este artigo busca responder tal questão por meio de uma pesquisa documental, almejando atualizar o pensamento do podcast para dar conta de sua apropriação educativa inclusiva. Para isso, serão relacionados diferentes referenciais teóricos na análise desenvolvida. Ao final, chegou-se a uma concepção que considera o podcast em suas esferas sonoras e textuais não como uma tecnologia de áudio, mas de oralidade.

Palavras-chave: Oralidade digital. Podcast escolar. Rádio educativo. Tecnologia de oralidade. Tecnologia educacional.

ABSTRACT The podcast for deaf people is the transcript of the speech of programs, eventually overcoming the current educational settings that, when analyzing the podcast, you see it as a tool characterized by the use of digital audio. Thus develops in the area a significant gap: how to define the nature of a podcast that exceeds its technological environment? This article seeks to answer this question through a documentary research, aiming to update the podcast thought to account for its inclusive educational appropriation. For this, they will be listed in different theoretical frameworks developed analysis. Finally, we arrived to a design that considers the podcast in its sound and textual spheres not as an audio technology but of orality.

Keywords: Digital orality. School podcast. Educational radio. Oral communication technology. Educational technology.

\section{INTRODUÇÃO}

A bibliografia da área que estuda educativamente o podcast aponta de forma relativamente consensual que o que caracteriza essa tecnologia é o uso de arquivos 
digitais de áudio. Nessa medida, o podcast é visto como constituído pelo uso de arquivos de áudio digital, similares àqueles aplicados na distribuição musical, para a veiculação de programas falados, assim como de músicas.

A apropriação social educativa daquela tecnologia, todavia, conta, desde 2010, com uma realização aparentemente contraditória: o podcast para surdos. Essa modalidade produtiva trata-se da transcrição textual das falas dos programas. A origem verbal de tal texto acaba por marcá-la como notadamente particular diante de elaborações originalmente escritas. Nessa medida, por dispor do modo expressivo informal das falas tipicamente encontradas no podcast brasileiro, a transcrição aludida acaba aglutinando oralidade e escrita em vista de replicar quesitos próprios da expressão oral da qual se origina, entretanto, ainda fazendo uso da escrita. Desta feita, tem-se no podcast para surdos uma modalidade produtiva que surgiu com tal título no Brasil por veicular em texto a oralidade dos programas nacionais.

O cenário apresentado acaba por acarretar a superação das definições do podcast vistas em seu campo de estudos educacionais. Diante dessa situação, emerge o problema: como definir a natureza de um podcast que suplanta seu meio tecnológico? Tal questão suscita a necessidade de caracterização de um podcast interposto entre a oralidade e a escrita, de modo a que se ofereça uma designação que contemple a atualidade de tal tecnologia.

O problema supracitado norteia este estudo, oriundo da tese "Podcast na educação brasileira: natureza, potencialidades e implicações de uma tecnologia da comunicação" (FREIRE, 2013b). O presente artigo buscará oferecer alternativa ao problema apresentado a partir da análise do podcast para surdos. Esse exame tentará aclarar a constituição da tecnologia em questão e, assim, prover para esta um novo alicerce conceitual, sintetizando tal perspectiva por meio de uma caracterização que concilie as múltiplas dimensões do uso educacional da tecnologia em análise.

Nos procedimentos que buscarão o alcance do objetivo apresentado, o podcast para surdos será objeto de uma reflexão que, partindo de uma pesquisa documental, buscará examinar a veiculação de um podcast em texto, de modo a investigar a relação entre o registro de falas em áudio e escrita. Essa estratégia será utilizada para que se tente identificar pontos em comum entre as esferas supracitadas, de modo a tomar as similaridades entre podcasts em som e em grafia 
como critério central de uma designação de tal tecnologia nas esferas que contempla. Desta feita, será dado seguimento às análises dispostas em um artigo anterior (FREIRE, 2011), que tratou do exame das implicações educativas do exercício nacional do podcast para surdos.

Para isso, inicialmente será investigada a bibliografia que versa sobre o podcast educativo. A ação descrita buscará desvelar o atual modo de designação acadêmica da tecnologia abordada. Posteriormente, a modalidade produtiva de podcast para surdos será analisada a fim de investigar sua relação com as definições levantadas na área do podcast educativo, de modo a observar se tais designações dão conta dos usos daquela tecnologia quando voltados para pessoas com deficiência auditiva. Em seguida, constatada a dissonância entre a concepção acadêmica e a apropriação social corrente do podcast, serão abordados os fatores que implicam o desencontro aludido. Nesse intuito, o exame do podcast para surdos partirá do levantamento das primeiras iniciativas de transcrição de podcasts em áudio para, em seguida, ser aprofundada a partir do exame da relação entre oralidade e escrita, dado à luz do referencial de Marcuschi $(2001 ; 2010)$ no concernente às visões do estudioso acerca do referido assunto.

A investigação descrita revelará a necessidade da aplicação de uma nova ótica tecnológica ao podcast, apta a dar conta do teor dinâmico da oralidade reproduzida por texto e áudio naquele âmbito tecnológico. Para o alcance disso, tal perspectiva buscará, na esfera da caracterização das tecnologias, privilegiar a apropriação social destas, cedendo aos aspectos técnicos dos objetos uma posição secundária. O desenvolvimento citado será norteado pelas ideias de Feenberg (2002; 2003) que abordam filosoficamente as acepções de essência (conceito subjetivo, convencional) e existência (materialidade) no campo das tecnologias. $O$ prisma tecnológico apresentado servirá como direcionador do desenvolvimento da definição de podcast que irá sintetizar os resultados das análises anteriores.

O conjunto dos procedimentos descritos servirá para a formulação de um pensamento capaz de esclarecer a natureza do podcast de modo a abarcar sua "escrita oral" voltada a pessoas com deficiência auditiva. Pretende-se, dessa forma, oferecer subsídios à maturação do pensamento educativo daquela tecnologia. Afinal, o desenvolvimento referido, é sensato afirmar, necessita partir de uma consideração mais abrangente da tecnologia tratada, de modo que se conte com uma definição 
que sintetize uma abordagem representativa da real constituição educativa do podcast nos dias de hoje.

\subsection{ATUAL DEFINIÇÃO EDUCATIVA DE PODCAST}

Nesta seção, será realizada uma revisão bibliográfica de estudos que buscam caracterizar o podcast, de forma a levantar o modo vigente de caracterização de tal tecnologia a fim de balizar reflexões posteriores do presente estudo. Vale salientar a incipiência do campo referido (FREIRE, 2013b). Tal esfera marca-se pela "escassez relativa dos estudos conduzidos no Brasil sobre esta temática" (BOTTENTUIT JUNIOR; LISBOA; COUTINHO, 2009, p. 297) - justifica o teor sucinto da aludida revisão.

Para Moura e Carvalho (2006, p. 88), o podcast é caracterizado estritamente por seus quesitos técnicos se tratando de uma "forma de publicação de programas de áudio, vídeo e imagens na internet". Igualmente, Lemos (2005) define tal tecnologia simplesmente como "um arquivo sonoro disponibilizado em um site". Já para Bottentuit Junior e Coutinho (2007, p. 839), "entende-se por podcast uma página, site ou local onde os ficheiros áudio estão disponibilizados para carregamento".

O foco nos meios é realizado também por Franco (2008, p. 55), que designa a tecnologia tratada como "uma programação de áudio, com diferentes tipos de registros (entrevista, palestra, exposição, aula) sobre os mais variados assuntos, disponibilizada na rede". Williams (2007, p. 1, tradução nossa) $)^{1}$, por sua vez, afirma que "podcast é um método para produzir conteúdo de áudio e vídeo disponível regularmente via web", também fazendo uso da definição técnica para conceituar essa tecnologia. A inclinação constatada é seguida por Furtoso e Gomes (2011, p. 1039) ao definirem podcast "como o próprio arquivo de áudio, publicado e disponível para download".

De modo similar, Assis, Salves e Guanabara (2010, p. 1) relatam que "Em linhas gerais, podcasts são programas de áudio, cuja principal característica é o formato de distribuição que os diferencia dos programas de rádio tradicionais e até de audioblogs e similares [...]". Já Medeiros (2006, p.3) designa a tecnologia em

\footnotetext{
${ }^{1}$ Podcasting is a method of making audio or video content available regularly via the Web.
} 
questão como uma "forma de produção descentralizada de conteúdo sonoro que disponibiliza os arquivos na internet para serem baixados quando o usuário bem entender". Cebeci e Tekdai (2006, n.p., tradução nossa²) seguem uma linha similar de foco nos quesitos técnicos na definição de podcast, designando-o como uma tecnologia para "distribuir conteúdos para serem usados com tocadores digitais móveis de áudio e vídeo como lpods, incluindo todos os outros tocadores de MP3, telefones celulares e PDAs".

Observa-se nas definições apresentadas que os estudiosos focam-se costumeiramente em critérios eminentemente técnicos na elaboração das diversas definições da tecnologia podcast. Portanto, é sensato afirmar que o exame das caracterizações do podcast na bibliografia educativa da área aponta a uma recorrente centralização no uso de arquivos digitais de áudio como critério de designação daquela tecnologia.

\subsection{O PODCAST PARA SURDOS}

O podcast para surdos consiste na transcrição textual das falas ditas nos programas. A não utilização de arquivos sonoros impossibilita que tais produções sejam contempladas pelas conceituações do podcast vistas em seu campo de estudo, as quais foram observadas na seção anterior. Assim, o aparente contrassenso da ideia de um "podcast para surdos" demanda uma reflexão detida para o esclarecimento de tal realização. Afinal, a confecção de podcasts voltados a pessoas com deficiência auditiva já constitui prática efetiva no Brasil, dada, inicialmente, por meio da realização de versões para surdos de episódios ${ }^{3}$ do "Podsemfio", podcast de Beatriz Kunze ${ }^{4}$ direcionado ao tratamento de temas relativos a tecnologias sem fio. "A realização da produção deu-se através da transcrição completa do episódio" (FREIRE, 2011, p.9), de forma a que o texto elaborado se aproximasse da fala dos participantes do programa.

A análise do projeto nacional supracitado necessita ser antecedida pela apresentação de elaborações prévias que tentaram direcionar o podcast a pessoas

${ }^{2}$ [...] to distribute content to be used with mobile and digital audio/video players such as iPods including all other MP3 players, cell phones and PDAs.

${ }^{3}$ As edições de podcasts são designadas na área como "episódios".

${ }^{4}$ Kunze é comentarista de tecnologia da rádio CBN Curitiba, do programa "Olhar Digital" da RedeTV e de diversas publicações on-line na área de tecnologia móvel. 
com deficiência auditiva. O projeto da British Sign Language pode ser citado como exemplo incipiente da busca em questão. A iniciativa lançou no ano de 2007 uma série de programas para ensinar aos surdos a língua britânica de sinais. Descrita como um "podcast para melhorar a comunicação com os surdos" 5 (tradução nossa), a produção utilizava o modo de distribuição do podcast, por meio de assinatura de conteúdo através de arquivos $x \mathrm{~m}^{6}$. Apesar disso, conforme afirma Freire (2012, p.7), é sensato não considerar aquela produção um podcast, mas um videocast ${ }^{7}$, na medida em que se foca na imagem tanto em seu conteúdo - linguagem visual de sinais -, quanto na própria tecnologia utilizada - o vídeo.

Publicações semelhantes - que, igualmente, intitulam-se podcasts - também são encontradas em outras partes do mundo. Um exemplo dessas produções é o Daily Devotions For The Deaf, programa americano cristão que faz uso do videocast utilizando a língua americana de sinais para disseminar dogmas bíblicos junto aos surdos. O projeto "CBN em Libras" traz, atualmente, aos surdos brasileiros materiais em vídeos que apresentam "[...] além de conteúdos recentes já traduzidos pelos intérpretes de Libras da ONG, o boletim 'Cidade Inclusiva', apresentado por Cid Torquato no CBN São Paulo [...]" (TAVARES, 2011). Embora utilize como base a oralidade, constata-se que essa produção é composta não por reprodução, mas por tradução de conteúdo oral para outra língua: a Língua Brasileira de Sinais - Libras. Por isso, é sensato assumir que aquela realização não poderia ser designada como um podcast para surdos (FREIRE, 2012, p. 7).

É válido afirmar que a efetiva elaboração de versões de podcasts voltados especificamente para pessoas com deficiência auditiva trata-se, como visto, da reprodução em texto das falas dos participantes dos programas. Contrariamente aos projetos previamente aludidos, esse conteúdo mantém uma ligação direta com a oralidade mesmo sem fazer uso de arquivos sonoros.

O processo de transcrição desenvolvido na elaboração de podcasts para surdos ocorre geralmente de forma cooperativa, também buscando prezar pela manutenção da fala original que reproduz. Tais parâmetros são seguidos desde a realização inicial desse tipo de produção, o episódio 94 do "Podsemfio", que tratou

\footnotetext{
5 Podcast to aid communication with the deaf. In: http://www.hearingaidknow.com/2007/05/08/bslpodcast-to-aid-communication-with-the-deaf/. Acesso em: 20 de janeiro de 2013.

${ }^{6}$ Formato de arquivos que contém um endereço para assinatura de um podcast via softwares como o ITunes,.

7 Podcasts cujo foco é direcionado a conteúdos audiovisuais.
} 
especificamente de tecnologias voltadas a pessoas com deficiência auditiva. No que diz respeito ao processo de transcrição deste podcast, sua produtora afirma:

\begin{abstract}
No próprio post [...] eu perguntei: olha, eu estou afim de fazer isso mas não posso transcrever tudo isso sozinha. Alguém topa participar, transcrever em equipe? Aí um grupo de dez pessoas mais ou menos se manifestou. Eu sempre converso com todos eles por e-mail e a gente vai revezando, cada um vai transcrevendo um podcast. [...] É fundamental: sempre peço para eles que a transcrição é passar a linguagem falada para o texto. A linguagem coloquial do dia a dia é transcrita para o texto para reproduzir as mesmas sensações, na medida do possível, do interlocutor na minha entrevista. Por exemplo, eu estou falando "então", "tipo", "assim", essas coisas de linguagem. Eu sempre peço para transcrever exatamente como foi falado. Claro, "errinhos" de concordância, essas coisas a gente corrige, mas a intervenção é bem suave e isso faz diferença. $O$ deficiente auditivo está ali lendo e está tendo a sensação de uma conversa coloquial mesmo (KUNZE, 2011, n. p.).
\end{abstract}

As transcrições das falas nos podcasts para surdos são distribuídas geralmente através de arquivos $p d f$ - formato digital de texto. Desta feita, por não serem sonoros, tais arquivos não poderiam ser considerados referentes a podcasts pela conceituação corrente. Entretanto, o caráter de reprodução da oralidade presente nesse conteúdo textual the possibilita gozar de grande parte da natureza dos programas falados, trazendo no texto, em grande medida, o modo de falar dos podcasts nacionais (FREIRE, 2012, p. 7).

O entendimento apresentado é sustentado pela constatação de que o acesso a podcasts para surdos, como o primeiro episódio de um podcast dessa modalidade, irá proporcionar a detecção de diversos modos expressivos típicos da fluência verbal. Algo perceptível em diversos trechos do programa referido, a exemplo da interlocução entre a apresentadora Beatriz Kunze e seu entrevistado no podcast em questão, o professor paulista Drauzio Júnior:

BIA: Então, professor, para começar, vamos falar um pouco de terminologia. Ao contrário do que as pessoas pensam, nem todo surdo é mudo, embora existam os surdos-mudos, certo?

DRAUZIO: Então, essa é uma questão muito importante para esclarecer (KUNZE, 2010, p. 3).

Percebe-se no trecho citado a reprodução de uma forma expressiva muito usada na fala verbal, principalmente na região Sudeste: o início de uma afirmação pelo uso do vocábulo "então" fora de suas funções gramaticais determinadas pela 
norma culta. A observação de outros momentos do podcast para surdos analisado leva igualmente a constatação da presença textual de modos verbais próximos da fala, algo perceptível no texto seguinte.

BIA: [...] existe alguma maneira de converter material de áudio em texto? DRAUZIO: Olha, Bia, isso aí existia um aparelho, um aparelho não, um software da IBM que se chamava ViaVoice (KUNZE, 2010, p. 4).

É possível observar na citação a autocorreção do falante durante sua própria afirmativa, de tal modo que o equívoco cometido não é omitido aos leitores que, desse modo, acabam por tomar contato com um texto que busca reproduzir em larga medida a oralidade expressa no programa. Tal privilégio à reprodução oral ampla em detrimento da concisão informativa textual é igualmente perceptível no mesmo episódio em outros momentos, como o que será veiculado a seguir, marcado pela interrupção da fala da apresentadora:

DRAUZIO: [...] telefone de deficiente auditivo. É um telefone que usa o que? Você coloca ele no aparelho e passa a se comunicar com a outra pessoas que também tem que ter o aparelho, por mensagem de texto.

BIA: Certo, então a outra pessoa...

DRAUZIO: O que ele faz, não há necessidade de utilizar a voz. A pessoa que precisa, o surdo precisa digitar, ele digita a mensagem e lê a resposta pela telinha! Entende?

$[\ldots]$

BIA: Ah, tá (KUNZE, 2010, p. 5-6).

No recorte aludido, detecta-se na segunda frase do docente a realização de uma pergunta em sua afirmativa, feita a fim de tornar mais didática a fala expressa. Esse expediente é típico de explicações orais em sala de aula ou de outras situações expositivas, como a própria circunstância vivenciada na realização da fala em análise. Além disso, constatam-se no texto os traços de uma fala voltada ao "bate-papo" quando o professor Drauzio, ao final, questiona se sua interlocutora compreendeu o que o docente acabara de explicar. O uso da expressão "coloca ele" ao invés de "coloca-o" exprime em igual medida o teor de reprodução de uma fala informal em texto.

As relações apontadas e afins são largamente observáveis em outros podcasts para surdos nacionais. O "Dispersando", dedicado a divulgar temas científicos a partir de uma atmosfera pouco formal, é um exemplo disso. Nesse 
podcast, o desenvolvimento cooperativo do processo das transcrições ocorreu quando "a partir de um movimento surgido no Twitter [...] formou-se uma equipe de pessoas dispostas a transcrever os podcasts" (ARANTES, 2010, n. p.). $\mathrm{Na}$ produção, trechos como os reproduzidos a seguir ilustram o teor oral do conteúdo da versão para surdos daquele podcast.

O que não é conversa é que teve uns caras lá no Reino Unido que eles fizeram uma pesquisa, era um censo na verdade, prá ver a população de cães e gatos lá que ninguém sabia. Tinha um chute, e daí eles descobriram que o chute que eles tinham dado era muito baixo, tipo, era cinco vezes mais gatos e cachorros na Grã Bretanha do que eles imaginavam. Então, aí tinha todo um censo. E o censo pesquisava também sobre as pessoas, né? Os donos dos bichos... Aí, o que eles descobriram? Que os donos dos bichos, os donos dos gatos são mais educados que os donos dos cachorros (SANTOS; SOARES; POLETTO, 2010, p. 3-4).

O texto contém diversos aspectos tipicamente direcionados à oralidade: a não omissão de vocativos, "[...] teve uns caras lá no Reino Unido que eles fizeram uma pesquisa"; realização de afirmações de forma interrogativa seguidas do vocábulo "né"; a repetição de termos informais, como "pra"; a utilização de elementos coesivos como "e daí", "Então, aí"; o uso de expressões fora de sua função gramatical culta, como a apropriação aplicada do termo "tipo".

No andamento da análise do podcast para surdos, todavia, é necessário esclarecer que o início da transcrição de podcasts para o formato texto remete aos primeiros anos após o surgimento da tecnologia, criada em 2004. Já em 2006, programas como o The Rude Guy anexavam no corpo de cada postagem a transcrição completa das falas do respectivo episódio veiculado em seu blog.

Segundo os achados desta pesquisa, a disponibilização para download de um arquivo digital contendo a transcrição de cada edição, por sua vez, foi inaugurada no ano seguinte, pela revista científica Science, que iniciou essa prática em seu podcast a partir daquele período. Vale salientar, todavia, que nenhuma dessas produções fez uso da definição "podcast para surdos", tampouco remeteu a intenção de suas transcrições ao atendimento do público de pessoas com deficiência auditiva. Em vista disso, é possível considerar, como já posto, o podcast de Beatriz Kunze como o primeiro podcast a realizar uma versão efetivamente confeccionada para o atendimento das necessidades dos surdos (FREIRE, 2012, p. 7). 
Nas relações desveladas por esta análise, é possível constatar que o podcast para surdos constitui-se por meio de uma relação de imbricação entre oralidade e escrita, na qual esta é utilizada para a veiculação oral. Desta feita, exercita-se nessa modalidade produtiva uma "mistura" em que o oral confunde-se com o escrito. É posta em causa, em vista disso, a concepção de uma natureza simetricamente apartada entre ambas as esferas citadas. Por essa razão, a constituição do podcast para surdos suscita a tomada de uma análise acerca da relação entre oralidade e escrita que ocorre nessas realizações. O procedimento descrito será realizado a seguir.

\section{A RELAÇÃO ENTRE ORALIDADE E ESCRITA}

Embora não se possa afirmar a partir de dados objetivos, as experiências sociais demonstram recorrentemente que a consideração apartada entre escrita e oralidade apresenta-se de forma hegemônica para o senso comum, constituindo a posição vigente no pensamento acerca da relação entre o oral e o escrito, em especial no contexto brasileiro. Concebe-se, nessa percepção, que falar é "fácil", fluído e empático, enquanto que escrever é "complicado", formal, provavelmente uma competência de "pessoas das letras". Por conseguinte, a fala é tida como instância educativa menor, "popular" no sentido pejorativo do termo, enquanto a escrita é vista como a manifestação típica dos "detentores do conhecimento".

É válido lembrar que o cenário apresentado se remete a uma concepção grafocêntrica disseminada pelo pensamento acadêmico anglo-saxão das décadas de 1960 e 1970. Tal concepção atribui à palavra escrita - tida como dicotômica à oralidade - o papel de detentora do exercício do raciocínio lógico (SIGNORINI, 2001) de tal modo que concebe como sinônimas as noções de alfabetização, enquanto aquisição do código escrito, e letramento, este entendido como instância de avanço educativo, ampliação de leitura de mundo, similar à perspectiva estabelecida por Freire (2001), para o qual se educar consiste em desenvolver uma leitura do mundo cada vez mais maturada. Têm-se, dessa forma, uma concepção que se poderia julgar equívoca, em razão de supor ignorância por parte dos não alfabetizados.

A disseminação do grafocentrismo constitui uma relação recursiva de teor paralisante aos iletrados. Por meio da propagação do entendimento de que os 
analfabetos (ou pouco alfabetizados) encontram-se distantes do pensamento lógico, reforça-se a valoração negativa desse grupo que, geralmente associado a classes de menor renda, já se vê costumeiramente agredido por valores desabonadores e privações relacionadas à sua condição econômica, tipicamente limitadora, por exemplo, do alcance a índices avançados de escolarização.

Por meio do encaminhamento referido, a valoração negativa das classes pobres é sublinhada. Assim, sujeitas aos quesitos paralisantes expostos, as classes acabam exercitando a usual defasagem formativa em relação às camadas mais abastadas da sociedade e, dessa maneira, dão ares de "verdade" à construção da leitura de supremacia dos detentores da competência escrita. $\mathrm{Na}$ relação apresentada, há o fortalecimento da naturalização do que Marcuschi (2010, p.10) qualifica como "mito da supremacia social e cognitiva da escrita sobre a oralidade". A perspectiva apontada dá-se por meio da consideração das características da escrita e da oralidade como naturais e imutáveis ${ }^{8}$, atestando-se, por exemplo, ser a última necessariamente dispersa. Tal consideração é contraposta pelos estudos do autor supracitado, no momento em que ele, em relação à oralidade e à escrita, afirma que

\begin{abstract}
Ambas permitem a construção de textos coesos e coerentes, ambas permitem a elaboração de raciocínios abstratos e exposições formais e informais, variações estilísticas, sociais, dialetais e assim por diante. As limitações e os alcances de cada uma estão dados pelo potencial do meio básico de sua realização: som de um lado e grafia de outro [...]. (MARCUSCHI, 2010 p. 17).
\end{abstract}

A contraposição à consideração dura da escrita e da oralidade pode ser realizada também a partir da mudança contextual, no que se refere ao recorte histórico observado. Para isso, feita uma remissão a meados do século $X V$, é possível observar, no pensamento acerca do oral e do escrito, uma relação distinta da atual, típica do contexto social vigente, naquele momento marcado por uma

[...] "oralidade mista": a escrita existe, mas o que conta é o que é dito, pronunciado pela voz e percebido pelo ouvido - a lei, nessa época, não é um texto escrito, mas a palavra do rei. Os arautos têm por função levá-la à

\footnotetext{
${ }^{8}$ Não é do interesse deste artigo discutir a presença ou não de aspectos estanques na fala e na escrita, mas, sim, pôr em causa percepções que concebam àquelas a partir de pensamentos naturalistas, estes configurados através de um entendimento a considerar de forma dura e apartada 0 oral e o escrito.
} 
praça pública e anunciar de "viva voz" aquilo que o rei decidiu (ZUMTHOR, 2005, p. 103-104).

No momento histórico em questão, a incipiência do desenvolvimento da escrita somada ao contexto político da época acabou por moldar de forma singular os aspectos hierárquicos da relação oral-escrito expressa no grafocentrismo. Desse modo, a valoração grafocêntrica estava invertida, com a escrita sendo vista como socialmente submissa à oralidade. A partir disso, reúnem-se subsídios para o entendimento do sentido não natural da leitura corrente acerca de oralidade e escrita. A referida concepção, no que diz respeito aos estudos da língua, apresentase superada, como aponta Marcuschi (2010). Este designa a percepção da existência de uma dicotomia imanente entre oral e escrito como relativa à tese da "grande virada" - em remissão a uma suposta mudança cognitiva decisiva introduzida pela escrita. Desse modo, Marcuschi denuncia o abandono daquele posicionamento dicotômico mesmo por seus próprios elaboradores, considerando que "evidentemente, essas teses não são mais sustentáveis hoje" (MARCUSCHI, 2010, p.17).

Norteado pelo entendimento de que "não há uma dicotomia real entre fala e escrita [...], realizações enunciativas da mesma língua em situações e condições de produção específicas e situadas" (MARCUSCHI, 2001, p. 47), é possível entender que ambas remetem-se a elaborações que, por suas próprias dinâmicas, associamse especificamente ao contexto de uso corrente. A perspectiva apresentada inicia-se pelo que se designou como visão do continuum fala-escrita. Por esse prisma, cuja constituição remonta a estudos realizados a partir da década de 1980, como os de Coulmas e Ehlich (1983), Nystrand (1982) e Tannen (1982), "constatava-se que tanto em termos de uso como de características linguísticas, fala e escrita mantinham relações muito mais próximas do que se admitia então" (MARCUSCHI, 2001, p.28).

Partindo de tal entendimento de aproximação entre fala e escrita, Marcuschi assume como pressuposto central a contextualização dos quesitos de fala e escrita de acordo com as realidades socioculturais vigentes. A sustentação dessa perspectiva pode ser elaborada a partir da observação de algumas situações de uso social de fala e escrita, apresentadas pelo teórico. No mundo árabe, por exemplo, em certos segmentos sociais ligados à doutrina muçulmana, a escrita é uma 
prerrogativa masculina, além de ocorrer apenas mediante ao pagamento de altas taxas.

Tais fatos acabam permeando as relações de poder naquela região, onde, para os leitores, são reservadas posições sociais de privilégio. O papel social da escrita aludido mostra-se pouco similar ao cenário brasileiro, por exemplo. Para apresentar mais um exemplo cabível neste momento, é possível afirmar que, caso se atente a um quadro de avisos de uma universidade, a noção de coesão imanente da escrita pode ser contraposta mediante ao quesito usualmente caótico de tal construção textual, na qual não se vê início nem fim no amontoado de notas acumuladas.

Outra percepção inata da escrita no tocante ao seu suposto teor de "frieza" e distanciamento é posta abaixo pela pesquisa de Shuman (1993), citada por Marcuschi (2001). O estudo trata da escrita colaborativa em narrativas entre adolescentes nos EUA. Na pesquisa, a autora observa, dentre outros casos, o uso da escrita por parte dos adolescentes como modo de aproximação, entre eles, como, por exemplo, através de declarações de amor mais "seguras", pois diminuiriam o risco de constrangimento por um possível "fora" dado por quem as recebe. Em virtude disso, Shuman atesta que

Os usos adolescentes da fala e da escrita ameaçaram a idéia de que a escrita é usada para criar distância autoritária e a fala é uma atividade face a face ou aproximativa. Constatei que os adolescentes usavam tanto a escrita como a fala para o distanciamento e a proximidade (SHUMAN, 1993, p. 247 apud MARCUSCHI, 2001, p. 33).

Shuman aponta que "a questão real não é a de 'como a escrita cria a possibilidade de um tipo de distância cognitiva', mas muito mais a questão de 'como formas particulares de escrita foram designadas como privilegiadas'” (1993, p. 247 apud MARCUSCHI, 2001, p. 34). Assim, ressalta-se novamente o caráter da relação entre oral e escrito como uma construção social dinâmica. Neste relacionamento, a oposição à tese da dicotomia entre ambas pode ser ampliada, por exemplo, a partir da observação de um contexto social cada vez mais disseminado: os chats, também conhecidos como bate-papos on-line. Estes possuem "características típicas da oralidade e escrita, constituindo-se [...] como um texto misto situado no entrecruzamento de fala e escrita" (MARCUSCHI, 2010, p. 18). 
Em vista disso, questiona-se: como, pela concepção apartada entre oralidade e escrita, conceber uma modalidade de troca de falas síncronas e informais que se dá a partir da escrita? Em contrapartida, de que modo é possível designar como oral um exercício que se dá mediante o uso da escrita? As questões apontadas oferecem subsídios para a apropriação de um entendimento não estático da oralidade e da escrita, concebendo-as de forma imbricada, concernente com o exercício daquelas entre os sujeitos.

Por essa razão, o relacionamento entre oralidade e escrita revela-se apto a ser observado a partir de um viés que busca não reproduzir tentativas de naturalização de construções sociais do grafocentrismo acadêmico, tampouco reverberar as concepções superficiais do senso comum relacionadas ao campo em questão. Por esse olhar, aqui tomado, a oralidade revela-se como um conjunto de práticas ligadas diretamente à fala, tanto no que se refere à emissão vocal propriamente dita quanto à transposição do oral para a grafia.

A escrita, por sua vez, é aqui considerada como uma realização dada nativamente pela grafia, marcada não pelo intento principal de reproduzir uma fala direta, mas pautada pelo compromisso de elaborar expressões a partir de uma estrutura textual gráfica. Contudo, tal entendimento não demarca uma separação entre o oral e o escrito, mas oferece parâmetros para um melhor entendimento das relações dinâmicas dadas entre aquelas instâncias no podcast para surdos.

Oralidade e escrita, portanto, apontam terem similaridades e dissonâncias como relativas aos contextos de exercício daquelas nas mais diversas instâncias: geográficas, hierárquicas, pessoais, históricas e tantas outras. Assim, a relação entre a oralidade e a escrita desvelada pela investigação dada nesta seção esclarece a imbricação entre aquelas, oferecendo alicerce ao esclarecimento da constituição expressiva do podcast para surdos, modalidade em que o escrito assume uma dinâmica oral. Tal constatação direciona a percepção do podcast como uma tecnologia não vinculada a um quesito material, seja o arquivo sonoro ou os dados digitais de texto, mas a uma prática humana: a oralidade.

Neste momento, emerge a questão: como associar a mudança da concepção de uma tecnologia a partir de alterações que não se centralizem em aspectos materiais, no objeto tecnológico, mas na prática expressiva deste? A elucidação dessa dúvida demanda uma reflexão acerca de qual concepção tecnológica poderia 
atender ao problema posto. A análise em questão será posta em curso na seção seguinte.

\section{REPENSANDO A CONCEPÇÃO DE "TECNOLOGIA" POR UMA ÓTICA EDUCATIVA}

A partir das demandas advindas do exame do podcast para surdos, pretende-se neste momento construir uma concepção de tecnologia cujo foco propicie a retirada dos quesitos materiais de um aparato como critério único de caracterização de uma tecnologia. Neste sentido, tal ótica tecnológica será desenvolvida de modo a esclarecer sua justificativa, construção e implicações para com o pensamento educativo que busca atualizar a caracterização do podcast para surdos. Assim, o prisma tecnológico referido buscará eleger o uso das tecnologias pelos sujeitos como principal critério a pautar a caracterização da tecnologia em análise neste texto.

No início do desenvolvimento da perspectiva tecnológica almejada, é necessário observar que "a partir de sua consideração fundamentalmente técnica, a tecnologia constitui um conjunto de técnicas reunidas em objetos - materiais ou imateriais - formatados para o aprimoramento de certos processos aos quais se aplicam" (FREIRE, 2013a, p. 37), de tal modo que são tidas como tecnologia a caneta, o carro, as letras, a TV, o desenho e tantos outros. Partindo-se desse viés, portanto, a tecnologia consiste no objeto ou técnica utilizados para um "fazer". Esta concepção suscita a realização de uma reflexão analítica acerca da visão exposta.

Feenberg (2003) apresenta o pensamento contemporâneo concernente à tecnologia como distinto da concepção adotada na Grécia antiga, para a qual "Nós, os humanos, não somos os mestres da natureza, mas trabalhamos com seus potenciais para trazer à fruição um mundo significativo" (FEENBERG, 2003, p. 4). Assim, o estudioso aponta o modo de pensar do homem de hoje como relativo a um entendimento para o qual a natureza constitui quase que estritamente matéria prima para manipulação, concepção, essa, que subverte o entendimento anterior de submissão do animal ao meio natural. Em vista desse modo de relação, torna-se pertinente a afirmativa de que "para nós, as essências são convencionais em lugar de reais. O significado e propósito das coisas é algo que criamos e não que descobrimos" (FEENBERG, 2003, p. 4). 
Assumindo-se o viés exposto, é consequente a consideração da tecnologia a partir de seu uso convencionado, não "descoberto" pelo exame dos objetos naturais ou tateamento dos aspectos objetivos da técnica. As implicações de tal perspectiva direcionam-se ao entendimento de que a concepção de "tecnologia" torna-se mais adequada, a partir de quesitos educativos, se concebida através de critérios que se balizem por aspectos que contemplem o teor abstrato e subjetivo observado nas tecnologias. Dessa forma, a utilização de definições conceituais em detrimento das técnicas, é sensato afirmar, emerge como alternativa de adequação do pensamento atual da tecnologia ao teor vigente de sua apropriação educacional. No entendimento referido, cabe salientar, considera-se "conceito" enquanto convenção, elaboração abstrata e subjetiva.

Nesse direcionamento, mais que dado técnico objetivo, a tecnologia é tida como um conceito sinônimo de um "fazer humano" que, como qualquer outro, existe mais por seu propósito social que por suas formas. Desse modo, inverte-se o vetor da visão tradicional de tecnologias na educação, de modo que seu foco mova-se da técnica inserida em certa prática social, como apontado por Oliveira (1977), para a centralização em uma prática social dada no âmbito da técnica. Aproxima-se, por essa mudança, de uma visão que entende a tecnologia como um "conjunto de discursos, práticas, valores e efeitos sociais ligados a uma técnica particular num campo particular" (LINARD, 1996, p. 191 apud BELLONI, 2003, p. 53).

Em razão da reflexão apresentada, chega-se a uma concepção na qual a tecnologia consiste no "fazer" por meio de um objeto ou técnica, não no objeto ou técnica utilizado para tal prática. O "fazer" aludido engloba as linguagens utilizadas, bem como o modo de relação com a tecnologia (produção/distribuição). Assim, manifesta-se uma perspectiva de separação entre essência (conceito) e existência (objetividade) que remonta à filosofia platônica, para a qual "a idéia, a essência da coisa é assim uma realidade independente da própria coisa em si e do fabricante da coisa" (FEENBERG, 2003, p. 3).

A partir do entendimento exposto, é possível desviar a definição fundamentalmente técnica de uma definição conceitual do podcast para surdos. Enquanto a primeira elenca as características técnicas como critério de designação de tal tecnologia, uma definição conceitual foca-se, em contrapartida, na utilização humana dos objetos tecnológicos, constitutiva de seu conceito, este remissivo à 
essência descrita pelos gregos. Tais critérios, pelo viés aqui delineado, não abandonam a técnica, mas a retiram do papel principal na elaboração das definições no campo em questão. Desta feita, apresenta-se um viés que pode oferecer alicerce para a caracterização educacional do podcast a partir do momento em que esta tecnologia demonstra ultrapassar seu objeto técnico, o áudio digital.

\subsection{PODCAST: TECNOLOGIA DE ORALIDADE}

A ótica tecnológica conceitual viabiliza a reelaboração dos critérios de designação e das próprias definições de podcast atualmente utilizadas, de modo a abordar o problema que norteia a presente pesquisa. Desse modo, o uso de uma definição conceitual da tecnologia direciona o foco da caracterização do podcast para surdos no que se faz por este, não no objeto pelo qual se realizam suas produções. A conciliação da dimensão sonora com a inclusiva do podcast demanda que o critério supracitado seja tomado para designar em educação qualquer modalidade dessa tecnologia.

Para atender a visão proposta, é necessário considerar para definição do podcast a prática central dada no uso dessa tecnologia. Assim, como já visto, é possível observar que o uso do podcast é centralizado na reprodução das manifestações orais dos sujeitos, seja em áudio ou texto. Desta feita, constata-se que o podcast se trata, essencialmente, de reprodução de oralidade por um meio tecnológico, portanto, uma tecnologia de oralidade. Nessa ótica, uma tecnologia de oralidade trata-se daquela que permite a sofisticação do manejo da oralidade em suas instâncias de produção e distribuição, seja pelo uso material do áudio ou do texto. Portanto, a oralidade tecnológica é constituída por tecnologias distintas: podcast e rádio (FREIRE, 2012, p. 17) bem como pelo podcast para surdos.

Esta última tecnologia, assim como as demais supracitadas, atuam para que a oralidade suplante significativamente o cessar das ondas vocais de um cenário natural de emissão da voz humana. Essa ampliação advém tanto da emissão em broadcasting, típica do rádio, quanto pela distribuição sob demanda, própria do podcast. Neste âmbito, é válido qualificar as tecnologias de oralidade nele inseridas como promotoras de uma "oralidade digital", a qual se constitui da oralidade tecnológica cuja sofisticação do manejo advém do uso de meios digitais. 
A partir do direcionamento explicitado, é possível cunhar uma conceituação de podcast que concilie suas dimensões textuais e sonoras, definindo-o como um modo de produção/disseminação livre de programas distribuídos sob demanda e focados na reprodução de oralidade, também podendo veicular músicas/sons. Diante da definição cunhada, é possível até mesmo falar de podcasts "pré-digitais", em referência a programas marcados pelos mesmos aspectos livres do podcast, porém distribuídos por sujeitos que utilizaram outros objetos de tecnologia: fitas cassete, transcrição em papel de debates, CDs e afins.

Diante das análises e reflexões realizadas, é sensato afirmar que a perspectiva do podcast aqui constituída a partir de uma ótica tecnológica conceitual demonstra dar conta da atual apropriação de tal tecnologia em sua modalidade voltada a pessoas com deficiência auditiva, bem como abarca sua utilização relacionada a arquivos digitais sonoros. Desta feita, o prisma desenvolvido reforça a tese de que para a educação o podcast não se veicula estritamente a seus objetos técnicos, mas tem na ampliação da oralidade sua caracterização como tecnologia educacional inclusiva.

\section{CONSIDERAÇÕES FINAIS}

A consideração central de quesitos técnicos na caracterização do podcast foi constatada como patente na bibliografia que trata do pensamento educativo daquela tecnologia, a qual acaba definida pelo uso de arquivos sonoros digitais. Nesse cenário, o desenvolvimento de uma "oralidade escrita" no podcast para surdos acabou por ultrapassar as aludidas definições. Assim, foi possível observar que o uso de designações tecnológicas balizadas por critérios estritamente técnicos pode mostrar-se inadequado ao pensamento da tecnologia educacional.

No cenário em questão, o exame da relação entre oralidade e escrita apontou, apoiado no referencial de Marcuschi $(2001 ; 2010)$, para o caráter dinâmico e imbricado daquelas instâncias, características, estas, que se percebeu viabilizarem a realização de podcasts para surdos, pautados pela quebra de uma perspectiva de rigorosa divisão entre o oral e o escrito. No âmbito de tais produções, originadas a partir da apropriação social do podcast no Brasil, a análise das particularidades do texto transcrito de uma fala em comparação a uma elaboração originalmente escrita 
sustentaram a perspectiva de imbricação entre o escrito e o oral, indicando a viabilidade de reprodução deste último por grafia.

O contexto em pauta suscitou a necessidade da inserção da modalidade voltada para surdos na caracterização do podcast em sua área de estudos educativos. Para efetivação desse objetivo, desenvolveu-se, aproveitando-se das ideias de Feenberg (2002; 2003), uma ótica tecnológica conceitual que visa caracterizar as tecnologias na educação a partir de critérios não focados nos objetos técnicos, mas na apropriação produtiva destes pelos sujeitos, de tal modo que as tecnologias sejam educativamente definidas por sua essência (ideia, conceito), não designadas estritamente a partir de sua existência (aspectos materiais dos aparatos).

Em vista disso, este artigo desenvolveu uma concepção que entende o podcast para surdos não como uma tecnologia de textos digitais, mas de oralidade. A mesma concepção aplica-se ao podcast sonoro. Desta feita, a análise do podcast para surdos ocasionou o desenvolvimento de uma visão teórica que concilia o podcast inclusivo ao seu conhecido similar sonoro, para isso, percebendo a oralidade como passível de reprodução tanto plenamente por áudio, quanto parcialmente por letras.

Assim, o podcast foi percebido como uma tecnologia de oralidade, modalidade que diz respeito às tecnologias que promovem a sofisticação do manejo da oralidade nos campos produtivos e distributivos, independente do objeto tecnológico que utilizem. Constatou-se ser válido que o grupo de tecnologias supracitado, quando inserido no âmbito digital, seja considerado detentor de uma "oralidade digital", a qual oferece às tecnologias de oralidade os aspectos próprios da produção e distribuição digitais.

Os procedimentos realizados implicaram 0 desenvolvimento de uma caracterização da tecnologia tratada que acabou sintetizada em uma definição particular. Esta, aponta o podcast como um modo de produção/disseminação livre de programas distribuídos sob demanda e focados na reprodução de oralidade, também podendo veicular músicas/sons. A conceituação oferecida revelou dar conta do atual estágio de apropriação educativa daquela tecnologia, aclarando a natureza da "escrita oral" do podcast para surdos e atualizando a caracterização de tal 
tecnologia de forma a preencher a lacuna observada no pensamento de seu campo de estudos educativos.

\section{EUGÊNIO PACCELLE AGUIAR FREIRE}

Graduado em Jornalismo, Mestre e Doutor em Educação, todos pela Uuniversidade Federal do Rio Grande do Norte (UFRN). É professor de Tecnologia Educacional do Instituto Metrópole Digital (UFRN). Sua área de estudos trata da apropriação educacional de ambientes on-line e tecnologias digitais, concentrando-se atualmente na investigação do uso da oralidade digital na educação, especificamente no que concerne à tecnologia podcast.

\section{REFERÊNCIAS}

ARANTES, A. Podcast Dispersando do SBBr: agora em versão transcrita!. Blog $O$ Divã de Einstein: A Ciência explicando as suas esquisitices!. 29 de julho de 2010. Disponível em: <http://odivadeeinstein.wordpress.com/2010/07/29/podcastdispersando-do-sbbr-agora-em-versao-transcrita/>. Acesso em: 10 ago. 2013.

ASSIS, P.; SALVES, D.; GUANABARA, G. O podcast no Brasil e no mundo: democracia, comunicação e tecnologia In: Simpósio Nacional ABCiber, 4, 2010, Rio de Janeiro. O podcast no Brasil e no mundo: democracia, comunicação e tecnologia. Rio de Janeiro, 2010. Acesso em: 10 fev. 2013.

BELLONI, M. Educação a Distância. $3^{\text {a }}$ ed. São Paulo: Editora Autores Associados, 2003.

BOTTENTUIT JUNIOR, J. B.; COUTINHO, C P. Podcast em Educação: um contributo para o estado da arte. In: IX CONGRESSO INTERNACIONAL GALEGO PORTUGUÊS DE PSICOPEDAGOGIA, Coruña. Podcast em Educação: um contributo para o estado da arte. 2007. p. 837-846. Disponível em:

<http://repositorium.sdum.uminho.pt/handle/1822/7094>. Acesso em: 20 jan. 2011.

BOTTENTUIT JUNIOR, J. B.; LISBÔA, E. S.; COUTINHO, C. P. Podcast: uma revisão dos estudos realizados no Brasil e em Portugal. In: CARVALHO, A. A. (org.). Actas do Encontro sobre Podcasts. Braga: CIEd, p. 293-298, 2009a. Disponível em: <http://repositorium.sdum.uminho.pt/handle/1822/9421>. Acesso em: 16 nov. 2012.

CEBECI, Z.; TEKDAL, M. Using Podcasts as Audio Learning Objects. Interdisciplinary Journal of Knowledge and Learning Objects, v. 2, 2006. Disponível em: <http://ijklo.org/Volume2/v2p047-057Cebeci.pdf>. Acesso em: 12 abril 2017.

COULMAS, F.; EHLICH, K. (Org.). Writing in focus. Nova York: Mouton, 1983. 
FEENBERG, A. Transforming technology. A critical Theory revisited. Tradução Carlos Alberto Jahn. New York: Oxford University Press, 2002. p. 3-35.

FEENBERG, A. O que é a filosofia da tecnologia? Komaba: 2003. Disponível em:<http://www.ige.unicamp.br/site/aulas/132/Feenberg_Filosofia_da_Tecnologia.pd f>. Acesso em: 17 fev. 2011.

FRANCO, C. M. S. S. As possibilidades do podcast como ferramenta midiática na educação. In: CARVALHO, A. A. (org.). Actas do Encontro sobre Podcasts. Braga: CIEd, p. 287-292, 2009. Disponível em:

<http://repositorium.sdum.uminho.pt/bitstream/1822/10052/4/Actas\%20do\%20Encont ro\%20sobre\%20Podcasts.pdf>. Acesso em: 16 nov. 2012.

FREIRE, E. P. A. Conceito educativo de Podcast: um olhar para além do foco técnico. Educação, Formação \& Tecnologias, v. 6, n. 1, p. 35-51, $2013 a$.

FREIRE, E. P. A. Distinções educativas entre rádio e podcast. Revista Prisma.com, 2012. Disponível em: <http://revistas.ua.pt/index.php/prismacom/article/view/1418>. Acesso em: 15 jul. 2013.

FREIRE, E. P. A. O podcast como ferramenta de inclusão. Revista Educação Especial, v.24, n. 40, maio/ago. 2011. Disponível em:

$<$ http://cascavel.ufsm.br/revistas/ojs-

2.2.2/index.php/educacaoespecial/issue/view/210/showToc>. Acesso em: 03 nov. 2011.

FREIRE, E. P. A. Podcast na educação brasileira: natureza, potencialidades e implicações de uma tecnologia da comunicação. Natal, 2013b. Tese (Doutorado em Educação). Centro de Ciências Sociais Aplicadas, Universidade Federal do Rio Grande do Norte.

FREIRE, P. A importância do ato de ler: em três artigos que se completam. 41 ed. São Paulo: Cortez, 2001.

FURTOSO, V. B.; GOMES, M. J. Aprendizagem e avaliação da oralidade em contextos online: o potencial dos serviços de podcasting. In: CONGRESSO INTERNACIONAL SOBRE AVALIAÇÃO EM EDUCAÇẪO, 2, 2011. Aprendizagem e avaliação da oralidade em contextos online - o potencial dos serviços de podcasting. Braga, Portugal, 2011. p. 1035-1052. Disponível em: <http://repositorium.sdum.uminho.pt/bitstream/1822/12854/3/gomes-viviane.pdf>. Acesso em: 26 mar. 2011.

KUNZE, B. Entrevista oral (via podcast) concedida a Eugênio Paccelli Aguiar Freire. Maio de 2011.

KUNZE, B. Podsemfio n. 94 - Deficientes auditivos. Blog Garota Sem Fio. 25 de junho de 2010. Disponível em: <http://www.garotasemfio.com.br/podcast/2010/06/25/podsemfio-n-94-deficientesauditivos>. Acesso em: 10 ago. 2013. 
LEMOS, A. Podcast. Emissão sonora, futuro do rádio e cibercultura. 404nOtFOund, n.12, junho de 2005. Disponível em:

<http://www.facom.ufba.br/ciberpesquisa/404nOtF0und>. Acesso em: 17 mar. 2011.

LINARD, M . Des Machines et des Hommes. Paris: L'Harmattan, 1996.

MARCUSCHI, L. A. Da fala para a escrita: atividades de retextualização. 10 ed. São Paulo: Cortez, 2010.

MARCUSCHI, L. A. Letramento e oralidade no contexto das práticas sociais e eventos comunicativos. In: SIGNORINI, Inês (Org.). Investigando a relação oral/escrito e as teorias do letramento. Campinas: Mercado das Letras, 2001 p. 2350 .

MEDEIROS, M. S. Podcasting: um antípoda radiofônico. In: SOCIEDADE BRASILEIRA DE ESTUDOS INTERDISCIPLINARES DA COMUNICAÇÃO. 29은 Congresso Brasileiro de Comunicação. Brasília, 6-9 set. 2006. Disponível em: <http://www.ufrgs.br/estudioderadio/wpadmin/textos/convergencia_tecnologica_ferrareto.pdf>. Acesso em: 15 nov. 2012.

MOURA, A.; CARVALHO, A. A. Podcast: Uma ferramenta para Usar Dentro e Fora da Sala de Aula. In: JOSÉ, R.; BAQUERO, C. (Eds): Proceedings of the Conference on Mobile and Ubiquitous Systems. Universidade do Minho: Guimarães, 2006. p. 155-158.

NYSTRAND, M. (org.). What Writers Know: the language, Process and Structure of Written Discourse. Nova York: Academic Press, 1982.

OLIVEIRA, J. B. A. Tecnologia educacional: uma estratégia de inovação. In: OLIVEIRA, J. B. A. (Org.). Perspectivas da tecnologia educacional. São Paulo: Pioneira, 1977.

SANTOS, I.; SOARES, R.; POLETTO, F. Dispersando - Episódio 1. 2010. Disponível em:

<http://meiodecultura.files.wordpress.com/2010/07/transcricaodispersando1.pdf>. Acesso em: 10 ago. 2013.

SHUMAN, A. Collaborative writing: appropriating power or reproducing authority? In: STREET, B. (ed.). Cross-cultural approaches to literacy. Cambridge: Cambridge University Press, p. 247-271, 1993.

SIGNORINI, I. (Org.). Investigando a relação oral/escrito e as teorias do letramento. Campinas: Mercado das Letras, 2001.

TANNEN, D. The Myth of orality and literacy. In: FRAWLEY, W.(Org.). Linguistics and literacy. Proceedings of the Delaware Symposium on language Studies. Nova York: Plenum, 1982. 
TAVARES, M. CBN em Libras. Disponível em: < http://cbn.globoradio.globo.com/vezdavoz/home.htm>. Acesso em: 18 abr. 2011.

WILLIAMS, B. Educator's Podcast Guide. Washington: ISTE, 2007. Disponível em:<http://www.breitlinks.com/podcastsforlearning/PodcastPDFs/EducatorsPodcast Guide.pdf>. Acesso em: 14 mar. 2011.

ZUMTHOR, P. Escritura e Nomadismo: entrevistas e ensaios. São Paulo: Ateliê Editorial, 2005. 